\title{
Self-inflicted pain out of boredom
}

Citation for published version (APA):

Nederkoorn, C., Vancleef, L., Wilkenhöner, A., Claes, L., \& Havermans, R. C. (2016). Self-inflicted pain out of boredom. Psychiatry Research, 237, 127-132. https://doi.org/10.1016/j.psychres.2016.01.063

Document status and date:

Published: 30/03/2016

DOI:

10.1016/j.psychres.2016.01.063

Document Version:

Publisher's PDF, also known as Version of record

Document license:

Taverne

Please check the document version of this publication:

- A submitted manuscript is the version of the article upon submission and before peer-review. There can be important differences between the submitted version and the official published version of record.

People interested in the research are advised to contact the author for the final version of the publication, or visit the DOI to the publisher's website.

- The final author version and the galley proof are versions of the publication after peer review.

- The final published version features the final layout of the paper including the volume, issue and page numbers.

Link to publication

\footnotetext{
General rights rights.

- You may freely distribute the URL identifying the publication in the public portal. please follow below link for the End User Agreement:

www.umlib.nl/taverne-license

Take down policy

If you believe that this document breaches copyright please contact us at:

repository@maastrichtuniversity.nl

providing details and we will investigate your claim.
}

Copyright and moral rights for the publications made accessible in the public portal are retained by the authors and/or other copyright owners and it is a condition of accessing publications that users recognise and abide by the legal requirements associated with these

- Users may download and print one copy of any publication from the public portal for the purpose of private study or research.

- You may not further distribute the material or use it for any profit-making activity or commercial gain

If the publication is distributed under the terms of Article $25 \mathrm{fa}$ of the Dutch Copyright Act, indicated by the "Taverne" license above, 


\title{
Self-inflicted pain out of boredom
}

\author{
Chantal Nederkoorn ${ }^{\mathrm{a}, *}$, Linda Vancleef ${ }^{\mathrm{a}}$, Alexandra Wilkenhöner ${ }^{\mathrm{a}}$, Laurence Claes ${ }^{\mathrm{b}}$, \\ Remco C. Havermans ${ }^{a}$ \\ a Department of Clinical Psychological Science, Maastricht University, Maastricht, The Netherlands \\ ${ }^{\mathrm{b}}$ Department of Clinical Psychology, KU Leuven, Leuven, Belgium
}

\section{A R T I C L E I N F O}

\section{Article history:}

Received 3 June 2015

Received in revised form

7 December 2015

Accepted 27 January 2016

Available online 28 January 2016

\section{Keywords:}

Emotion regulation

Non-suicidal self-injury

Shock

Sensation seeking

Affective style

\begin{abstract}
A B S T R A C T
Previous research has shown that in response to a monotonous, boring lab situation, non-clinical participants voluntarily self-administer electric shocks. The shocks probably served to disrupt the tedious monotony: they were the only available external source of stimulation. Alternatively, the shocks might have functioned to regulate the negative emotional experience caused by the induction of boredom, consistent with theories on the function of non-suicidal self-injury (NSSI). According to this latter explanation, induction of other negative emotions would also increase the administration of shocks. To test this explanation, 69 participants watched a monotonous, sad or neutral film fragment, during which they could self-administer electric shocks. Participants in the boredom condition self-administered more shocks and with higher intensity, compared to both the neutral and sadness condition. Sadness had no effect on the self-administration of shocks. The effect of boredom was more pronounced in participants with a history of NSSI: they administered more shocks in the first $15 \mathrm{~min}$. The results indicate that the shocks function to disrupt monotony and not to regulate negative emotional experience in general. Moreover, boredom appears an important impetus for NSSI.
\end{abstract}

(c) 2016 Elsevier Ireland Ltd. All rights reserved.

\section{Introduction}

Boredom is considered an unpleasant emotion that arises when an individual is unable to engage in satisfying activity and attributes this to the context, which is perceived as uninteresting or lacking of stimulation (Eastwood et al., 2012). An experimental manipulation to induce feelings of boredom typically exists of offering monotonous stimulation for a prolonged time. Interruptions of the task decrease feelings of boredom, especially if the task is simple and demands little attention (Fisher, 1993). Further, asking participants to entertain themselves with their thoughts only is considered unpleasant and boring (Wilson et al., 2014). Wilson and colleagues found that their study participants even preferred aversive stimulation (i.e., an electric shock) to being left alone with their thoughts only.

The study by Wilson et al. (2014) was not aimed at studying the effect of boredom and they did not compare a stimulus-deprived condition to a stimulus-rich condition. It is therefore not possible to conclude that stimulus deprivation leads to boredom that in turn motivates people to shock themselves when given the opportunity to do so. Indeed, the participants might simply have

\footnotetext{
* Corresponding author.

E-mail address: c.nederkoorn@maastrichtuniversity.nl (C. Nederkoorn).
}

shocked themselves because they could: out of curiosity, not out of boredom. However recently, Havermans et al. (2015) showed that when people are offered the opportunity to disrupt monotony with alternative stimulation, they are likely to do so. In their experiment, participants were randomly divided into two conditions: a neutral condition in which they watched a documentary for one hour, and a boring condition in which they had to watch one short fragment of the same documentary over and over again for one hour. In both conditions, participants had free access to either chocolate (experiment 1 ) or electric shocks (experiment 2 ). In the monotonous, boring condition, people ate more chocolate and they shocked themselves more often and with a higher intensity, compared to the respective neutral conditions. The authors concluded therefore, alike Wilson et al. (2014), that boredom is aversive to such an extent that some people even prefer negative stimuli above monotony.

There is another explanation why participants might choose to shock themselves. According to Chapman's Experiential Avoidance Model (Chapman et al., 2006), deliberate self-harm, also called non-suicidal self-injury (NSSI), has the function to avoid or escape from aversive emotional experiences. NSSI refers to purposefully inflicting harm to one's body and includes behaviors like scratching, cutting, hitting or burning oneself (Whitlock et al., 2006; Claes et al., 2010). The mechanism behind NSSI is not 
completely clear yet: NSSI might elicit endogenous opioids, which alleviates pain and emotional distress or the physiological stimulation might serve as distraction and help to shift attention from emotional pain towards physical pain (Chapman et al., 2006). NSSI is more common in psychiatric populations, but also reported frequently in the general population (Whitlock et al., 2006; Claes et al., 2010). Among adolescence, the frequency is estimated to lie between 13\% and 23\% (Jacobson and Gould, 2007; Muehlenkamp et al., 2012) and among college students it was found that between 17\% (Whitlock et al., 2006) and 41\% (Aizenman and Jensen, 2007) reported the occurrence of at least one NSSI incident. The most important function of NSSI appears affect-regulation: people reported decreased negative affect, relief and increased positive affect directly after NSSI (Chapman et al., 2006; Klonsky, 2007; Claes et al., 2010). It seems therefore possible that in the studies of Havermans et al. (2015) and Wilson et al. (2014), voluntarily administering electric shocks might have served to cope with the negative emotional experience caused by the induction of boredom. This would imply that if another negative emotion is induced, again part of the participants would choose to administer electric shocks, in order to avoid experiencing the negative emotion.

In addition, it is expected that participants with a history of NSSI revert to painful stimulation during aversive emotions in the lab more easily. Self-administering electric shocks can be considered a proxy of NSSI behavior (Franklin et al., 2013), behavior these participants have shown before. In addition, participants with a history of NSSI are found to have higher pain thresholds (Claes et al., 2006; Hooley et al., 2010), making it likely they would self-administer electric shocks with a higher intensity.

In the present study, the two alternative explanations are tested. Participants are randomly divided between 3 conditions: a boredom condition, a sadness condition and a neutral condition. Participants will view film fragments, during which they can voluntarily choose to self-administer electric shocks. The number of the shocks within the first $15 \mathrm{~min}$ and within one hour will be tested. These two time periods are used in the studies of respectively Wilson et al. (2014) and Havermans et al. (2015) respectively and allow to study the effect of short and prolonged mood induction. Besides the number of shocks, the maximum intensity of the shocks that participants choose will be tested. It is hypothesized that participants in the boredom and sadness condition will self-administer more electric shocks and shocks with a higher maximum intensity, compared to the neutral condition.

\section{Method}

\subsection{Participants}

The study was approved by the Ethical Committee of the Faculty of Psychology and Neuroscience, Maastricht University. Sample size was based on a medium effect size (in Havermans et al. (2015) a large effect of the boredom manipulation was found $\left(\eta_{\text {partial }}^{2}=0.41\right)$, but the effect size of the sadness manipulation on self-administration of shocks was unknown and therefore estimated as medium). When employing an alpha rejection criterion of 0.05 and a power of 0.80 , we needed 65 participants for the current research design. We therefore aimed to test between 65 and 70 participants. Seventy participants registered, all undergraduate university students. After registration, participants were informed about the exclusion criteria for the current study (neural or cardiovascular disorders, pregnancy). No participants were excluded. During the testing of one participant, the apparatus did not function. A total of 69 participants are thus included in the analyses (56 women, 13 men, $M$ age $=22.17$ years, $S D=2.67$ ).

\subsection{Materials}

\subsubsection{Mood induction}

Participants were randomly assigned to the neutral, boredom or sadness condition. During the neutral condition, participants watched a 60 min segment of the 95 min documentary In Search of Memory (Seegers, 2009). This documentary depicts the life and research on memory of the Nobel laureate and neuroscientist Eric Kandel. During the boredom condition, participants watched an $83 \mathrm{~s}$ fragment out of the same documentary. In this fragment Kandel is playing a game of indoor tennis with a friend. The fragment was repeated 43 times for a total of $60 \mathrm{~min}$. During the sad condition participants watched a 60 min fragment of the somber movie My sister's keeper (Furst et al., 2009). The movie is about a girl who was born as a savior sibling in order to donate bone marrow, blood or other organs, so her older sister can fight leukemia.

\subsubsection{Questionnaires ${ }^{1}$}

2.2.2.1. Mood. Participants were asked to rate how bored, happy, sad, frustrated, angry, anxious, tensed, tired, nervous, safe, and helpless they felt that moment on $10 \mathrm{~cm}$ visual analog scales (VAS), ranging from 0 ('not at all') to 100 ('very much').

Based on the affect grid of Russell (Russell et al., 1989, Russell and Feldman Barrett, 1999; Mandryk et al., 2006) two composite scores were made: the emotions with the most negative valence (sadness, anger, boredom, fear, frustration and, negatively scored, happiness) were added to form an index for negative valence. In addition, the emotions with the most arousal (nervousness, tenseness and, negatively scored, tiredness) were added as an index for arousal.

2.2.2.2. History of NSSI. Participants filled out the Self-Injury Questionnaire (SIQ; Claes and Vandereycken, 2007). This scale contains questions about 5 types of non-suicidal self-injurious behavior and gives participants the possibility to add a sixth. Of each behavior, the incidence is asked on a 5 points scale, ranging from “'last week' to" 'never'. Only when participants report the occurrence of a behavior within the last month, more questions about the behavior are asked. In the present study, participants will be either identified as having a life-time history of NSSI or not (0-1). For being identified as having a history of NSSI, participants must have engaged in at least one type of NSSI during life-time.

\subsubsection{Electro-cutaneous stimulation}

Two $8 \mathrm{~mm}$ electrodes (filled with hypertonic gel; spaced $2 \mathrm{~cm}$ apart) were attached to the inside of the non-dominant lower arm. The electrodes connected the participant to a bipolar constant current stimulator (DS5, Digitimer, Hertfordshire, UK), which is able to administer a $300 \mathrm{~ms}$. electric shock, sinus wave: $50 \mathrm{~Hz}$, between 1 and $20 \mathrm{~mA}$ (intensity selected by the participant). The number of self-administered electric shocks after 15 min and after $1 \mathrm{~h}$, and the highest selected intensity of the shock (the highest current) were registered.

\subsection{Procedure}

After signing an informed consent form, electrodes were attached and participants were explained how they could administer an electric shock, if they would choose to do so. The participants were explained that they could self-administer an electro-

\footnotetext{
${ }^{1}$ Exploratively, the Sensation Seeking Scale (Zuckerman, 2007) and the concealing subscale of the ASQ (Hofmann and Kashdan, 2010) were measured. No significant effects or relations with the other variables were found. More details can be found in Supplemental information.
} 
cutaneous shock by first selecting on the computer the intensity of the shock (varying between 1 and $20 \mathrm{~mA}$ ) and then pressing the space bar. Note that participants were not familiarized with the sensation of different shock intensities. However, they were advised that if they would choose to administer a shock, they should start with $1 \mathrm{~mA}$ intensity level, which produces a mild sensation. If they would like to continue with applying electric shocks, they should gradually increase the intensity, to avoid unexpected intense painful stimulation.

Mood was rated with the VAS scales and next, participants were randomly assigned to the boredom, sadness or neutral condition. Next, all participants saw a film fragment, lasting one hour, during which the participants could self-administer electric shocks. Afterwards, electrodes were removed and participants rated their mood again. Participants were asked to fill out the SSS, ASQ and SIQ questionnaires and finally, each participant received a debriefing and could choose a course credit or a 10-euro gift certificate as reward for participation.

\subsection{Statistical analyses}

As a manipulation check, the mood scores on the VAS scales were tested with a MANOVA, with condition (neutral, sadness and boredom) and history of NSSI (yes or no) as between subjects variables and emotional changes (post minus pre) as dependent variables. In addition, the composite scores of valence and arousal were tested with two ANOVAs. For significant effects, post-hoc tests were performed, Bonferroni corrected.

Three separate 3 (condition: neutral, sadness and boredom) $\times 2$ (History of NSSI: yes or no) ANOVA's were used to test differences in the number of self-administered electric shocks within $15 \mathrm{~min}$, within one hour and the maximum selected intensity of the shocks.

In addition, the relations between the amount and intensity of shocks, self-reported boredom and sadness after the film fragments were tested with bivariate Pearson correlations.

Two outliers in the number of shocks within one hour and 3 outliers in the number of shocks within 15 min were identified ( $>$ 3SD above the mean), all in the boredom condition. Because these extreme values are considered an effect of the manipulation and not an error, we chose not to exclude these values but replace them with the nearest number of shocks of the total sample (see Wilcox (2001)) $)^{2}$.

\section{Results}

\subsection{Participant characteristics}

Scores on the questionnaires and demographic characteristics per condition are shown in Table 1.

\subsection{Manipulation check}

The three conditions appeared effective in manipulating different emotions, $F(26,108)=4.90, p<0.001, \eta_{\text {partial }}^{2}=0.500$, see Fig. 1. No effects of history of NSSI on emotions was found, $F(11$, $53)=0.578, p=0.838, \eta_{\text {partial }}^{2}=0.107$ and the interaction between condition and history of NSSI was also not significant, $F(22,108)=$ $1.09, p=0.373, \eta_{\text {partial }}^{2}=0.181$. When looking at the main effect of condition, effects were found for:

\footnotetext{
${ }^{2}$ The analyses with unchanged values or exclusion of these values showed the same patterns and would lead to the same conclusions.
}

(1) boredom, $F(2,66)=23.96, p<0.001, \eta_{\text {partial }}^{2}=0.421$, with participants feeling more bored in the boredom condition as compared to both the neutral $(p<0.001)$ and sad condition $(p<0.001)$;

(2) sadness, $F(2,66)=20.09, p<0.001, \eta_{\text {partial }}^{2}=0.378$, with participants feeling more sad, compared to both the neutral $(p<0.001)$ and boredom condition $(p<0.001)$

(3) happiness, $F(2,66)=5.66, p=0.005, \eta_{\text {partial }}^{2}=0.146$, with participants feeling less happy in the sad condition, compared to the neutral condition $(p=0.004)$;

(4) frustration, $F(2,66)=5.64, p=0.005, \eta_{\text {partial }}^{2}=0.146$ with participants in both the boredom $(p=0.013)$ and sadness condition $(p=0.017)$ feeling more frustrated relative to the neutral condition;

(5) tiredness, $F(2,66)=15.76, p<0.001, \eta_{\text {partial }}^{2}=0.323$, with participants in the boredom condition feeling more tired, compared to the sad $(p<0.001)$ and neutral condition $(p=0.001)$;

(6) helplessness, $F(2,66)=4.43, p=0.016, \eta_{\text {partial }}^{2}=0.118$, with participants in the sad condition feeling more helpless relative to the neutral condition $(p=0.012)$.

No effects of the manipulation were found on anxiety, anger, tenseness, nervousness and safety (all $F s<2.11$ ).

In addition, condition had a significant main effect on the valence-composite score, $F(2,68)=7.26, p=0.001, \eta_{\text {partial }}^{2}=0.187$, with participants in the sad and boredom condition reporting more negative affect compared to the neutral condition $(p=0.003$ and $p=0.001$ ). The sad and boredom condition did not differ from each other $(p=1)$. History of NSSI had no significant main or interaction effect $(F s<2.45)$.

Condition also had a significant main effect on the arousalcomposite score, $F(2,68)=3.53, p=0.035, \eta_{\text {partial }}^{2}=0.10$, with participants in the sad condition reporting higher arousal than in the boredom condition $(p=0.025)$. The neutral condition did not differ from both the sadness $(p=0.43)$ and the boredom condition $(p=0.65)$. History of NSSI had no significant main or interaction effect $(F s<0.72)$.

\subsection{Electric shocks between conditions}

The first ANOVA tested the number of shocks within the first $15 \mathrm{~min}$. There was a main effect of condition $F(2,63)=4.83$, $p=0.011, \eta_{\text {partial }}^{2}=0.133$. This effect was qualified by a significantly interaction between condition and history of NSSI, $F(2,63)=3.74$, $p=0.029, \eta_{\text {partial }}^{2}=0.106$, see Fig. 2 for participants without a history of NSSI, condition had no effect on number of shocks within the first $15 \min , F(2,39)=0.57, p=0.57, \eta_{\text {partial }}^{2}=0.028$. For participants with a history of NSSI, condition had a significant effect $F$ $(2,24)=6.32, p=0.006, \eta_{\text {partial }}^{2}=0.345$. Post-hoc tests, Bonferroni corrected, showed that participants with a history of NSSI shocked more frequently in the boredom condition, compared to the neutral $(p=0.016)$ and the sadness condition $(p=0.020)$. The sadness and neutral condition did not differ from each other $(p=1)$.

The second ANOVA tested the number of shocks within one hour. There was a main effect of condition, $F(2,63)=13.78$, $p<0.001, \eta_{\text {partial }}^{2}=0.304$, see Fig. 2. Post-hoc tests, Bonferroni corrected, showed that participants in the boredom condition shocked more often than in both the sadness $(p<0.001)$ and the neutral condition $(p<.001)$. There was no significant difference between the neutral and the sadness condition $(p=0.89)$. History of NSSI had no main effect on number of shocks $F(1,63)=0.003$, $p=0.95, \eta_{\text {partial }}^{2}=0.0$, and did not interact with condition, $F(2,63)=$ $1.84, p=0.17, \eta_{\text {partial }}^{2}=0.06$.

The third ANOVA tested the maximum selected intensity of the shocks and showed a marginally significant main effect of condition, $F(2,40)=3.11, p=0.056, \quad \eta_{\text {partial }}^{2}=0.134$. Post-hoc tests, 
Table 1

Mean scores of the participants in the three conditions.

\begin{tabular}{|c|c|c|c|c|c|c|c|}
\hline & \multicolumn{2}{|c|}{ Neutral condition } & \multicolumn{2}{|c|}{ Sadness condition } & \multicolumn{2}{|c|}{ Boredom condition } & \multirow[t]{3}{*}{ Test of group differences } \\
\hline & \multicolumn{2}{|l|}{$n=23$} & \multicolumn{2}{|l|}{$n=23$} & \multicolumn{2}{|l|}{$n=23$} & \\
\hline & $M(S D)$ & $95 \% \mathrm{CL}$ & $M(S D)$ & $95 \% \mathrm{CL}$ & $M(S D)$ & $95 \% \mathrm{CL}$ & \\
\hline History of NSSI & $26.1 \%$ & & $47.8 \%$ & & $43.5 \%$ & & $\chi^{2}=2.56, p=0.279$ \\
\hline Scratch & $13 \%$ & & $30.4 \%$ & & $26.1 \%$ & & $\chi^{2}=2.12, p=0.347$ \\
\hline Bruise & $4.3 \%$ & & $4.3 \%$ & & $4.3 \%$ & & $\chi^{2}=0, p=1$ \\
\hline Cut & $17.4 \%$ & & $21.7 \%$ & & $4.3 \%$ & & $\chi^{2}=3.04, p=0.219$ \\
\hline Bite & $8.7 \%$ & & $4.3 \%$ & & $13 \%$ & & $\chi^{2}=1.1, p=0.578$ \\
\hline Different & 0 & & $8.7 \%$ & & 0 & & $\chi^{2}=4.1, p=0.127$ \\
\hline Recency of NSSI & & & & & & & $\chi^{2}=5.1, p=0.747$ \\
\hline Never & $73.9 \%$ & & $52.2 \%$ & & $56.5 \%$ & & \\
\hline$>1$ year & $17.4 \%$ & & $30.4 \%$ & & $17.4 \%$ & & \\
\hline Multiple months & 0 & & $4.3 \%$ & & $8.7 \%$ & & \\
\hline Month & $4.3 \%$ & & $8.7 \%$ & & $8.7 \%$ & & \\
\hline Week & $4.3 \%$ & & $4.3 \%$ & & $8.7 \%$ & & \\
\hline
\end{tabular}

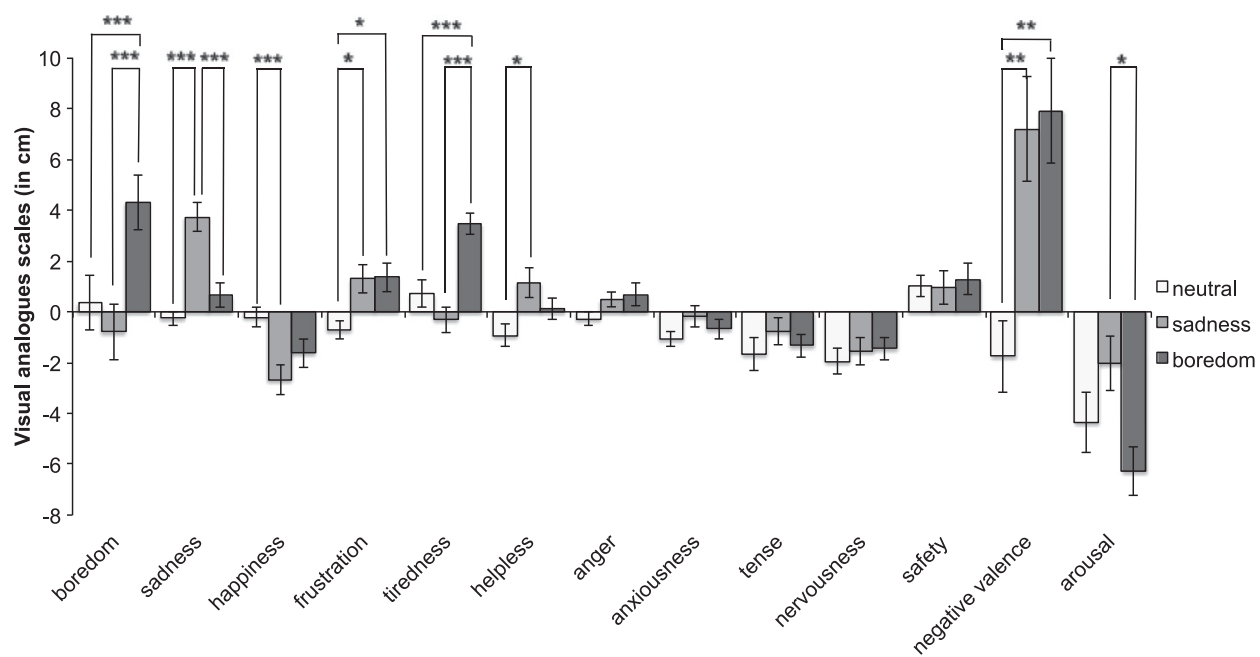

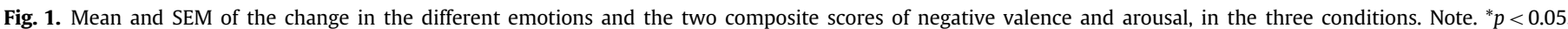
${ }^{* *} p<0.01,{ }^{* * *} p<0.001$.
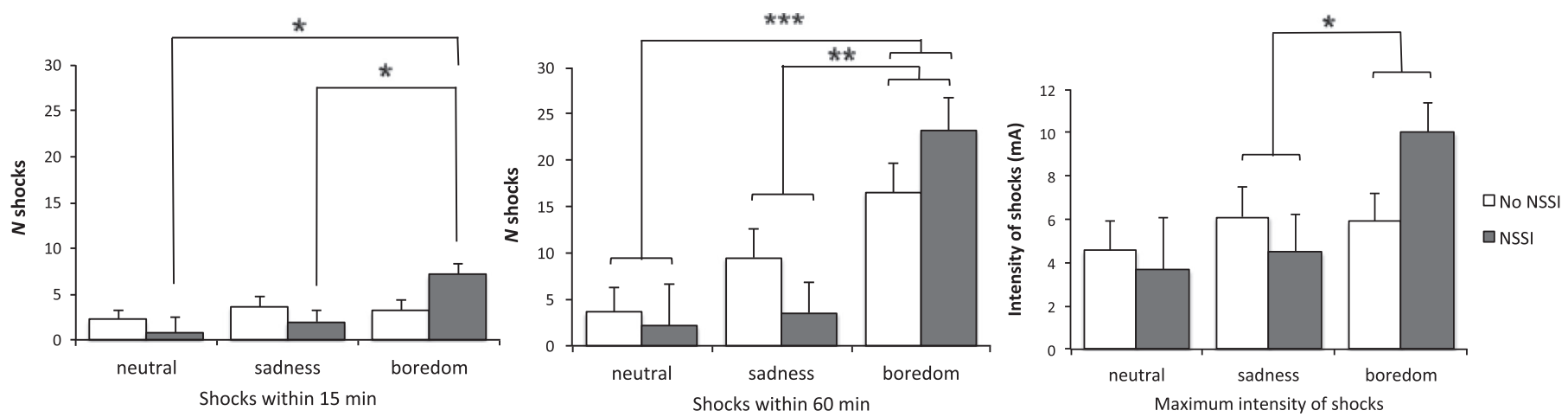

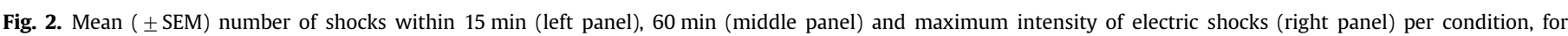
participants with and without a history of NSSI. Note. ${ }^{*} p<0.05,{ }^{* *} p<0.01,{ }^{* * *} p<0.001$.

Bonferroni corrected, showed a trend of participants in the boredom condition to shock with a higher intensity than in neutral condition $(p<0.085)$. There was no significant difference between the sadness condition and both the boredom $(p=0.32)$ and the neutral condition $(p=1)$. The main effect of history of NSSI was not significant, $F(1,40)=0.16, p=0.694, \eta_{\text {partial }}^{2}=0.004$. In addition, the interaction between history of NSSI and condition was not significant, $F(2,40)=2.23, p=0.12, \eta_{\text {partial }}^{2}=0.10$.

\subsection{Correlation between variables}

The correlations are reported in Table 2. It appeared that the number of shocks within $1 \mathrm{~h}$ was related to self-reported boredom after the film fragment. When looking at the participants without a history of NSSI, this same correlation was significant. In participants with a history of NSSI, the number of shocks within $15 \mathrm{~min}$, $1 \mathrm{~h}$ and the highest intensity were all significantly related to self- 
Table 2

Pearson correlations between self-reported boredom and sadness with shocking behavior, for all participants, participants with and without a history of NSSI.

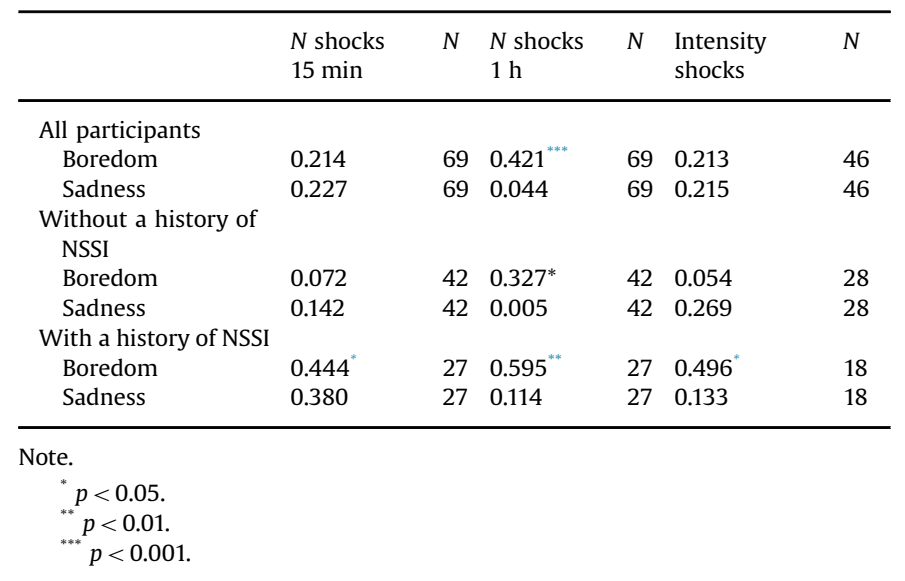

reported boredom after the film fragment. Self-reported sadness was not related to shocking behavior.

\section{Discussion}

The present study showed that, compared to a neutral condition, boredom significantly increased the number of voluntary, self-administered electric shocks, whereas sadness did not. In the first $15 \mathrm{~min}$, the effect of boredom was only noticeable in participants with a history of NSSI. After $1 \mathrm{~h}$, the effect of boredom was present in both groups, with and without a history of NSSI. Boredom also tended to increase the maximum selected intensity of the shocks in the boredom condition. Again, the sadness condition did not have an effect, compared to the neutral condition. In the whole group and in the participants without a history of NSSI, self-reported boredom was related to the number of shocks, selfadministered within one hour. The relation between self-reported boredom and shocking behavior appeared more prominent in the participants with a history of NSSI: in this group, significant correlations between boredom and shocking behavior within the first $15 \mathrm{~min}$, the whole hour and with intensity of shocks were found.

The finding that boredom increased the number of self-administered electric shocks, whereas sadness did not, suggests that the electric stimulation served specifically to interrupt the tedious monotony and not to regulate and avoid general negative emotional experiences. Note that the boredom and sadness conditions elicited equally strong self-reported emotions: no difference was found on the composite score of negative valence. The sadness condition elicited higher arousal, compared to the boredom condition. This indicates that the sadness induction was successful, but that this specific emotion did not trigger the demand for painful stimulation in these non-clinical participants. Of course it cannot be excluded that other emotions besides boredom could also influence self-administrations of electric shocks, like for example anger. It is also possible that the combination of negative valence and low-arousal is critical to trigger the behavior. This is suggested by Mercer and Eastwood (2010), who tested how boredom could lead to gambling behavior. They proposed two mechanisms, fairly similar to two possible functions we proposed: The low arousal state of boredom might induce a need for stimulation which gambling could provide, or the aversive emotional experience could induce a need for distraction or avoidance, again provided by gambling. Based on selfreports from a student sample, they concluded that most likely gambling is motivated by a low arousal and not by the avoidance of negative affect, which is in concordance with our findings.
In their study, Mercer and Eastwood (2010) assumed that boredom has both, a negative affect and low-arousal. In the literature, however, the effects of boredom on physiological arousal are inconsistent: both lower and higher skin conductance is found (London et al., 1972; Mandryk et al., 2006). In the present study, boredom also appeared to be a low-arousal emotion, which supports the conclusions of Mercer and Eastwood (2010). It would therefore be interesting to test the effects of a depressed mood on self-shocking behavior, which is also characterized by a negative valence and low-arousal (Russell and Feldman Barrett, 1999). That might reveal if indeed the combination of low-arousal and negative valence is important, or if a boring, monotonous situation is unique in evoking self-shocking behavior. For now, we only know that it is not a general negative valence alone that stimulates selfadministration of shocks.

During the induction of boredom, participants with a history of NSSI self-administered more electric shocks within the first 15 min, whereas the participants without a history of NSSI appeared more hesitant and showed no effect of the boredom at that moment. Possibly, the participants with a history of NSSI had less effective coping techniques to deal with the boredom, were more prone to interrupt the boring situation or experienced boredom sooner. We assume that $1 \mathrm{~h}$ of monotony is such a strong manipulation that group differences disappeared: participants in both groups resorted to shocking themselves. We want to point out we do not think shocking was an effective strategy to reduce boredom on the long run: probably it only had a short effect. Future research, in which boredom is measured more continuously throughout the experiment, might give more insight in the interplay between boredom and the administration of shocks over time.

The current lab study differed in several aspects from real life situations. In the present experiment, participants had only two options: they could endure the situation, or turn to electric shocks. They were not allowed to find other stimulation, like a cell phone, communication with other people or eating something. In daily life, most people would be inclined to look for other stimulation, leave or change the situation before they turn to painful stimulation. Although the current experimental setting allows us to study the influence of isolated aspects, in this case the emotions boredom and sadness, generalization to real life should only be made with care.

In addition, in this experiment a non-clinical sample of undergraduate students was tested. The majority of participants had no history of NSSI, or, if they had, it was more than a year ago. This means the participant might have had a healthy way of coping with the negative emotion of sadness. Perhaps a sample of clinical patients with current problems with NSSI would have reacted differently to the mood inductions. We know from the literature that emotional reactivity and less adequate coping with emotions are related to NSSI (Gratz, 2003; Plener et al., 2012). Moreover, other risk factors have been identified, like childhood abuse, decreased self-esteem, impulsiveness and psychological dysfunctioning, which can influence NSSI directly or in interaction with each other (Claes et al., 2001; Gratz, 2003; Laye-Gindhu and Schonert-Reichl, 2005). Clearly, the current model of NSSI which we used in the lab is a simplification.

As another limitation, it should be noted that the sample size was not that large and especially not for studying the effect of a history of NSSI or of the maximum shock intensity of those who applied shocks, therefore the current study might lack statistical power. Moreover, gender has shown an effect on the reaction to boredom in some studies (Wilson et al., 2014) and on NSSI in others (i.e. Laye-Gindhu and Schonert-Reichl, 2005). In the present study, only $19 \%$ men were included, which did not allow us to the study the effect of gender. Future studies are advised to also take 
gender into account.

With these limitations in mind, it is still remarkable that prolonged monotonous stimulation has such a large effect on the number of electric shocks that a non-clinical sample does selfadminister, especially when having a history of NSSI. It indicates that boredom might be an important factor in NSSI. Indeed, in the research literature concerning NSSI, participants sometimes report boredom as a motive for NSSI, although less frequent than other motives like anger, regulation of negative emotional arousal or self-punishment (Claes et al., 2001, 2010; Laye-Gundhu and Schonert-Reichl, 2005; Chapman and Dixon-Gordon, 2007; Klonsky, 2007; Nock et al., 2009). In addition, boredom appeared an important predictor of suicidal ideation or thoughts (Choquet et al., 1993; Ben-Zeev et al., 2012). With the use of experience sampling it has been found that $46 \%$ of NSSI behaviors were aimed to 'feel something', which included satisfaction, stimulation and pain (Selby et al., 2014). This aim might partly stem from feelings of boredom or weariness. It seems therefore possible that the role of boredom in NSSI is more important than generally believed. More research should be aimed at the role of boredom in NSSI, since this might have important implications for prevention or treatment of this behavior.

In addition, even in daily life monotonous situations cannot always be avoided. It can occur incidentally when having to wait for something, but also more frequently during specific work circumstances, school or in hospital situations. Moreover, in detention and psychiatry, solitary confinement and seclusion can lead to serious sensory deprivation. Indeed, solitary confinement in jail has been associated with increased risk of self-harm (Kaba et al., 2014). As the same mechanism can already be provoked in nonclinical undergraduate students within $1 \mathrm{~h}$, it seems that the negative effects of boredom and monotony should not be taken lightly.

In conclusion, the present study shows that especially boredom, and not sadness, provokes people to self-administer electric shocks. The effect of boredom was evident sooner in participants with a history of NSSI, who also applied shocks with a higher intensity when feeling bored. This suggests that the electric stimulation served to interrupt the monotony of the boredom condition and not to regulate and avoid general negative emotional experiences. Moreover, boredom appears to function as an important impetus for the initiation of NSSI, which is perhaps underestimated in the literature.

\section{Appendix A. Supplementary material}

Supplementary data associated with this article can be found in the online version at http://dx.doi.org/10.1016/j.psychres.2016.01. 063.

\section{References}

Aizenman, M., Jensen, M.A.C., 2007. Speaking through the body: the incidence of self-injury, piercing, and tattooing among college students. J. Coll. Couns. 10, $27-43$.

Ben-Zeev, D., Young, M.A., Depp, C.A., 2012. Real-time predictors of suicidal ideation: mobile assessment of hospitalized depressed patients. Psychiatry Res. 197, 55-59.

Chapman, A.L., Dixon-Gordon, K.L., 2007. Emotional antecedents and consequences of deliberate self-harm and suicide attempts. Suicide Life-Threat 37, 543-552.

Chapman, A.L., Gratz, K.L., Brown, M.Z., 2006. Solving the puzzle of deliberate selfharm: the experiential avoidance model. Behav. Res. Ther. 44, 371-394.

Choquet, M., Kovess, V., Poutignat, N., 1993. Suicidal thoughts among adolescents: an intercultural approach. Adolescence 28, 649.
Claes, L., Vandereycken, W., 2007. The self-injury questionnaire-treatment related (SIQ-TR): construction, reliability, and validity in a sample of female eating disorder patients. In: Goldfarb, P.M. (Ed.), Psychological Tests and Testing Research Trends. Nova Science Publishers, New York, pp. 111-139.

Claes, L., Vandereycken, W., Vertommen, H., 2001. Self-injurious behaviors in eating-disordered patients. Eat. Behav., 263-272.

Claes, L., Vandereycken, W., Vertommen, H., 2006. Pain experience related to selfinjury in eating disorder patients. Eat. Behav. 7, 204-213.

Claes, L., Klonsky, E.D., Muehlenkamp, J., Kuppens, P., Vandereycken, W., 2010. The affect-regulation function of nonsuicidal self-injury in eating-disordered patients: which affect states are regulated? Compr. Psychiatry 51, 386-392.

Eastwood, J.D., Frischen, A., Fenske, M.J., Smilek, D., 2012. The Unengaged mind defining boredom in terms of attention. Perspect. Psychol. Sci. 7, 482-495.

Fisher, C.D., 1993. Boredom at work: a neglected concept. Hum. Relat. 46, 395-417.

Franklin, J.C., Puzia, M.E., Lee, K.M., Lee, G.E., Hanna, E.K., Spring, V.L., Prinstein, M.J. 2013. The nature of pain offset relief in nonsuicidal self-injury: a laboratory study. Clin. Psychol. Sci. 1, 110-119.

Furst, S., Goldman, S., Johnson, M., Pacheco, C., Tropper, M. (Producers), Cassavetes, N. (Director), 2009. My Sister's Keeper [DVD]. United States: Curmudgeon Films.

Gratz, K.L., 2003. Risk factors for and functions of deliberate Self-Harm: an empirical and conceptual review. Clin. Psychol.: Sci. Pr. 10, 192-205.

Havermans, R.C., Vancleef, L., Kalamatianos, A., Nederkoorn, C., 2015. Eating and inflicting pain out of boredom. Appetite 85, 52-57.

Hofmann, S.G., Kashdan, T.B., 2010. The affective style questionnaire: development and psychometric properties. J. Psychopathol. Behav. Assess. 32, 255-263.

Hooley, J.M., Ho, D.T., Slater, J., Lockshin, A., 2010. Pain perception and nonsuicidal self-injury: a laboratory investigation. Personal. Disord. Theory, Res. Treat. 1 170.

Jacobson, C.M., Gould, M., 2007. The epidemiology and phenomenology of nonsuicidal self-injurious behavior among adolescents: a critical review of the literature. Arch. Suicide Res. 11, 129-147.

Kaba, F., Lewis, A., Glowa-Kollisch, S., Hadler, J., Lee, D., Alper, H., Selling, D., MacDonals, R., Solimo, A., Parsons, A., Venters, H., 2014. Solitary confinement and risk of self-harm among jail inmates. Am. J. Public Health 104, 442-447.

Klonsky, E.D., 2007. The functions of deliberate self-injury: a review of the evidence. Clin. Psychol. Rev. 27, 226-339.

Laye-Gindhu, A., Schonert-Reichl, K.A., 2005. Nonsuicidal self-harm among community adolescents: understanding the "whats" and "why" of self-harm. J. Youth Adolesc. 34, 447-457.

London, H., Schubert, D.S., Washburn, D., 1972. Increase of autonomic arousal by boredom. J. Abnorm. Psychol. 80, 29.

Mandryk, R.L., Atkins, M.S., Inkpen, K.M., 2006. A continuous and objective evaluation of emotional experience with interactive play environments. In: Proceedings of the SIGCHI Conference on Human Factors in Computing Systems. ACM, pp. 1027-1036.

Mercer, K.B., Eastwood, J.D., 2010. Is boredom associated with problem gambling behaviour? It depends on what you mean by 'boredom'. Int. Gambl. Stud. 10, 91-104.

Muehlenkamp, J.J., Claes, L., Havertape, L., Plener, P.L., 2012. International prevalence of adolescent non-suicidal self-injury and deliberate self-harm. Child Adolesc. Psychiatry Mental Health 6, 1-9.

Nock, M.K., Prinstein, M.J., Sterba, S.K., 2009. Revealing the form and function of self-injurious thoughts and behaviors: a real-time ecological assessment study among adolescents and young adults. J. Abnorm. Psychol. 118, 816.

Plener, P.L., Bubalo, N., Fladung, A.K., Ludolph, A.G., Lulé, D., 2012. Prone to excitement: adolescent females with non-suicidal self-injury (NSSI) show altered cortical pattern to emotional and NSS-related material. Psychiat. Res.: Neuroimaging 203, 146-152.

Russell, J.A., Feldman Barrett, L., 1999. Core affect, prototypical emotional episodes, and other things called emotion: dissecting the elephant. J. Personal. Soc. Psychol. 76, 805.

Russell, J.A., Weiss, A., Mendelsohn, G.A., 1989. Affect grid: a single-item scale of pleasure and arousal. J. Personal. Soc. Psychol. 57, 493.

Seegers, P. (Producer and Director)., 2009. In Search of Memory. [DVD]. United States: Icarus Films

Selby, E.A., Nock, M.K., Kranzler, A., 2014. How does self-injury feel? Examining automatic positive reinforcement in adolescent self-injurers with experience sampling. Psychiatry Res. 215, 417-423.

Wilcox, R.R., 2001. Fundamentals of Modern Statistical Methods: Substantially Improving Power and Accuracy. Springer, New York.

Wilson, T.D., Reinhard, D.A., Westgate, E.C., Gilbert, D.T., Ellerbeck, N., Hahn, C., Brown, C.L., Shaked, A., 2014. Just think: the challenges of the disengaged mind Science 345, 75-77.

Whitlock, J., Eckenrode, J., Silverman, D., 2006. Self-injurious behaviors in a college population. Pediatrics 117, 1939-1948.

Zuckerman, M., 2007. The sensation seeking scale V (SSS-V): still reliable and valid. Personal. Individ. Differ. 43, 1303-1305. 